\title{
Performance of Tall Buildings with and without Transfer Plates under Earthquake Loading
}

\author{
M T R Jayasinghe, D S Hettiarachchi and D S R T N Gunawardena
}

\begin{abstract}
The scarcity of valuable lands has created a leap in the tall building construction all over the world. Due to the mixed use of these buildings as commercial, residential, parking, etc., it has become essential to have different column grids in the same building to ensure the efficient use of space and materials. Use of transfer plates is one of the widely used methods to transfer gravity loads among different column grids. With lateral loads governing the design of tall buildings, it is essential to consider their behaviour against earthquake loads. This paper compares the behaviour of tall buildings with and without transfer plates against earthquake loading.
\end{abstract}

Keywords: $\quad$ Tall buildings, Response spectrum analysis, Earthquakes

\section{Introduction}

The availability of the usable urban lands is declining at a rapid rate due to development of cities. This has led to the construction of tall buildings with mixed development in the vicinity of the city centres since they can provide large office areas close to places well served by public transport. These tall buildings often require integrated parking facilities as well for which the space requirements are different from that of residential and office spaces in the rest of the building.

To ensure the effective usage of the tall building, it is important to have two different column grids in parking areas and the residential/ office areas. However, to transfer the gravity loads from one set of columns to the other, a load transfer system is required. Transfer beam systems and the transfer plate systems are the most widely used methods for this purpose. When planned with due consideration for lateral load behaviour, the structures with transfer plates can provide adequate behaviour with respect to wind induced acceleration (Balasuriya et.al. 2007).

With the use of transfer plates, mass distribution of the building could become highly irregular due to the thickness of the transfer plate.

Thus, it is advisable to analyse the behaviour of these buildings against earthquake loads under dynamic conditions, though many engineers still may use static analysis methods due to the reluctance to use dynamic analysis unless a complete 3D model of the structure is available.

In this study, the dynamic behaviour of a building with a transfer plate was compared with a similar building without a transfer plate, when subjected to earthquake loading using finite element models (FEM) developed with SAP 2000 software. The parameters used for the buildings are generally applicable to Sri Lankan conditions.

\section{Methodology}

The research was carried out using finite element models of two 35 storied apartment buildings of which one building consists of a transfer plate whereas the other building is uniform throughout.

Since the research was carried out in the Sri Lankan context, it was required to find earthquake data which are relevant to Sri Lankan conditions. Thus AS1170.4, Australian Standard for Earthquake Loads was used to obtain earthquake loads for the buildings.

AS 1170.4 was chosen as the best representation of Sri Lankan conditions due to following factors;

- The type of earthquakes that Sri Lanka may experience is intra-plate type which would be similar to that experienced by Australia as well.

- Sri Lanka and Australia lie on the same tectonic plate; i.e. Indo-Australian plate.

Eng. (Prof). M T R Jayasinghe, B.Sc. Eng (Moratuwa), Ph.D. (Cambridge), C.Eng., MIE(Sri Lanka), Senior Professor, Department of Civil Engineering, University of Moratuwa

Eng. D S Hettiarachchi, B.Sc. Eng (Moratuwa), Structural Engineer, Design Consortium Ltd.

Eng. $D$ S $S$ R $\quad T \quad N$ Gunawardena, B.Sc. Eng (Moratuwa), Structural Engineer, Design Consortium Ltd. 
- The types of tall buildings found in Australia are quite similar to those that would come up in Sri Lanka now; i.e. in 35 to 50 storey range with reinforced concrete frames.

Static and dynamic responses for the buildings were obtained in accordance with AS1170.4 for comparison purposes.

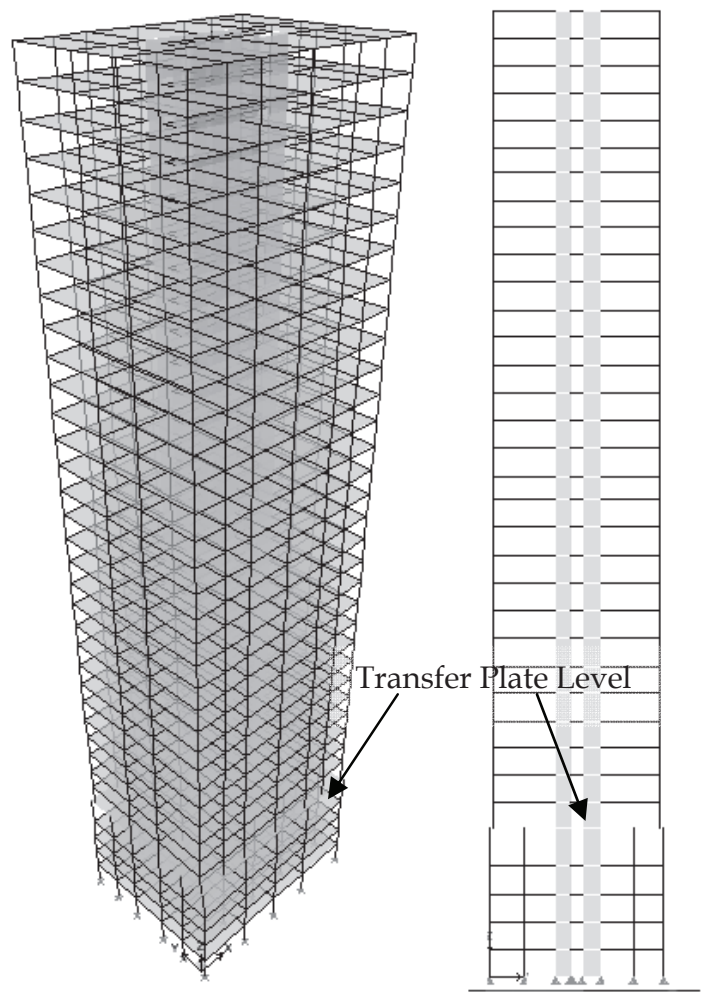

Figure 1a-FEM of the Building with Transfer Plate

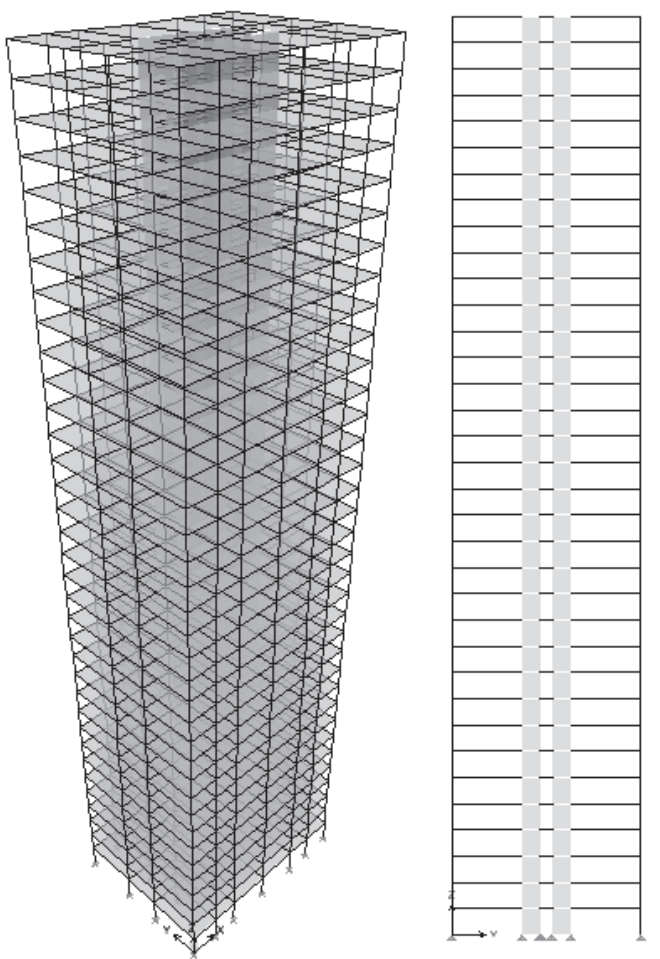

Figure 1b-FEM of the Building without Transfer Plate

\section{Case Study}

\subsection{General}

A rectangular layout with two axes of symmetry was chosen for the building models. The symmetry in turn would minimise effects of shape and mass distribution in the transverse direction. The transfer plate was taken to be $1.5 \mathrm{~m}$ thick. Section sizes were chosen to match the structural requirements.

\subsection{Finite Element Model}

Two 3D models were developed with SAP 2000, one with a transfer plate and 5 parking floors (with a different column arrangement) and the other without a transfer plate. These are shown in Figures1a and $1 \mathrm{~b}$ respectively.

The transfer plate was modelled with thick plate (Mindlin/Reissner) formulation to include the transverse shear deformation. When modelling the transfer plate, it is of utmost importance to make sure that all the column nodes coincide with the nodes in the finite element mesh of the transfer plate to ensure proper shear transfer through nodes. This was achieved by meshing the transfer plate manually.

However, the accuracy of the thick-plate formulation is more sensitive to large aspect ratios and mesh distortion than the thin-plate formulation (SAP2000 Analysis Reference, 2002). Thus the mesh was further refined to make the aspect ratios of the mesh as close to 1.0 as possible. The mesh achieved by this method is shown in Figure 2.

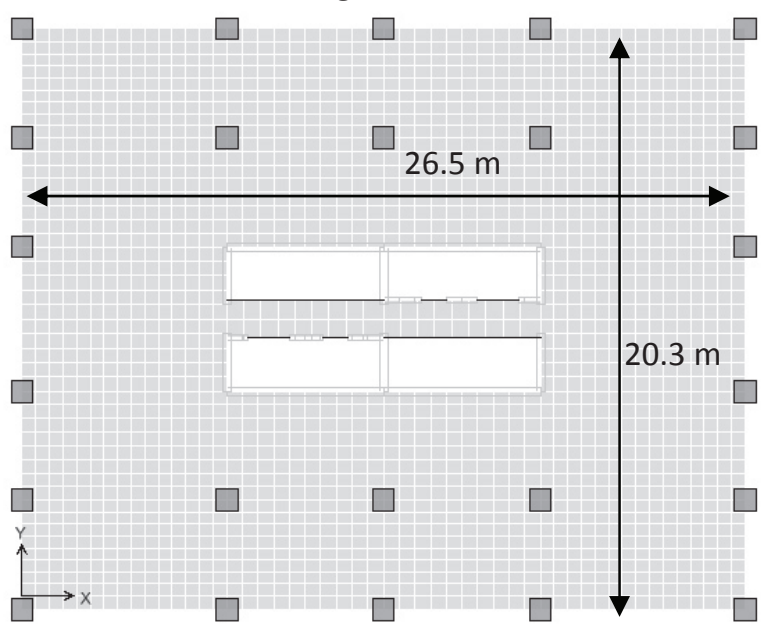

Figure 2 - Meshing of Transfer Plate 


\subsection{Analysis}

The static analysis was carried out in accordance with the Quasi-Static analysis procedure in AS1170.4. Response Spectrum Analysis was chosen as the dynamic method of analysis. The earthquake response spectrum in AS1170.4 was used.

Peak Ground Acceleration at rock sites for a $10 \%$ probability of exceedance in 50 year or 475 year return period is around $0.026 \mathrm{~g}$ for Colombo (Peiris, 2008). Further, Sri Lanka has not experienced significant earthquake activities in the recent past except for a few tremors. Since the emphasis is on the variation pattern of earthquake loads rather than on the magnitude, the use of an exact value of acceleration coefficient and its applicability to a particular region would be of less significance to this study. Therefore, purely to assess the performance of tall buildings with transfer plates slightly higher acceleration values in the range of $0.10 \mathrm{~g}-0.15 \mathrm{~g}$ were selected. Acceleration values in this range are well accommodated in the Australian standard AS 1170.4

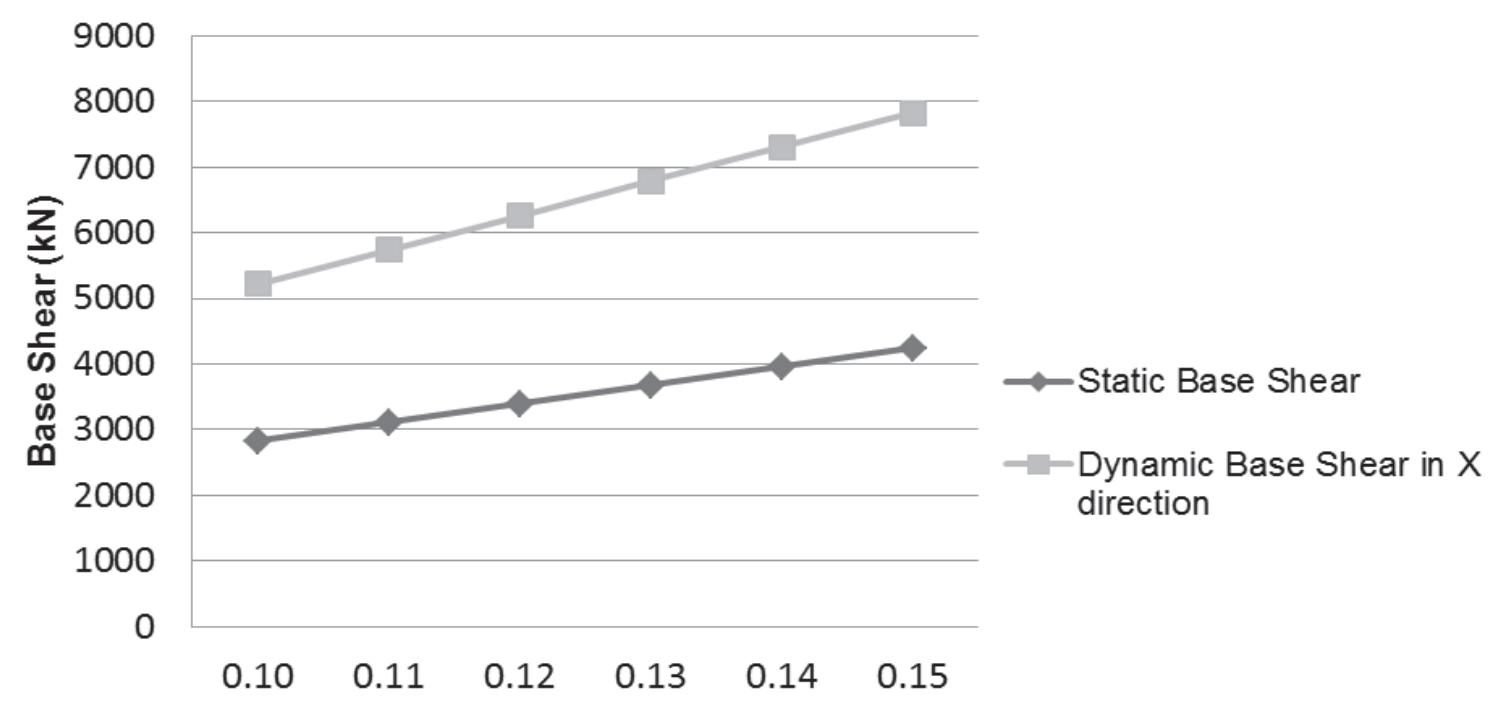

Acceleration Coefficient (g's)

Figure 3 - Acceleration Coefficient vs. Base Shear - Building with Transfer Plate

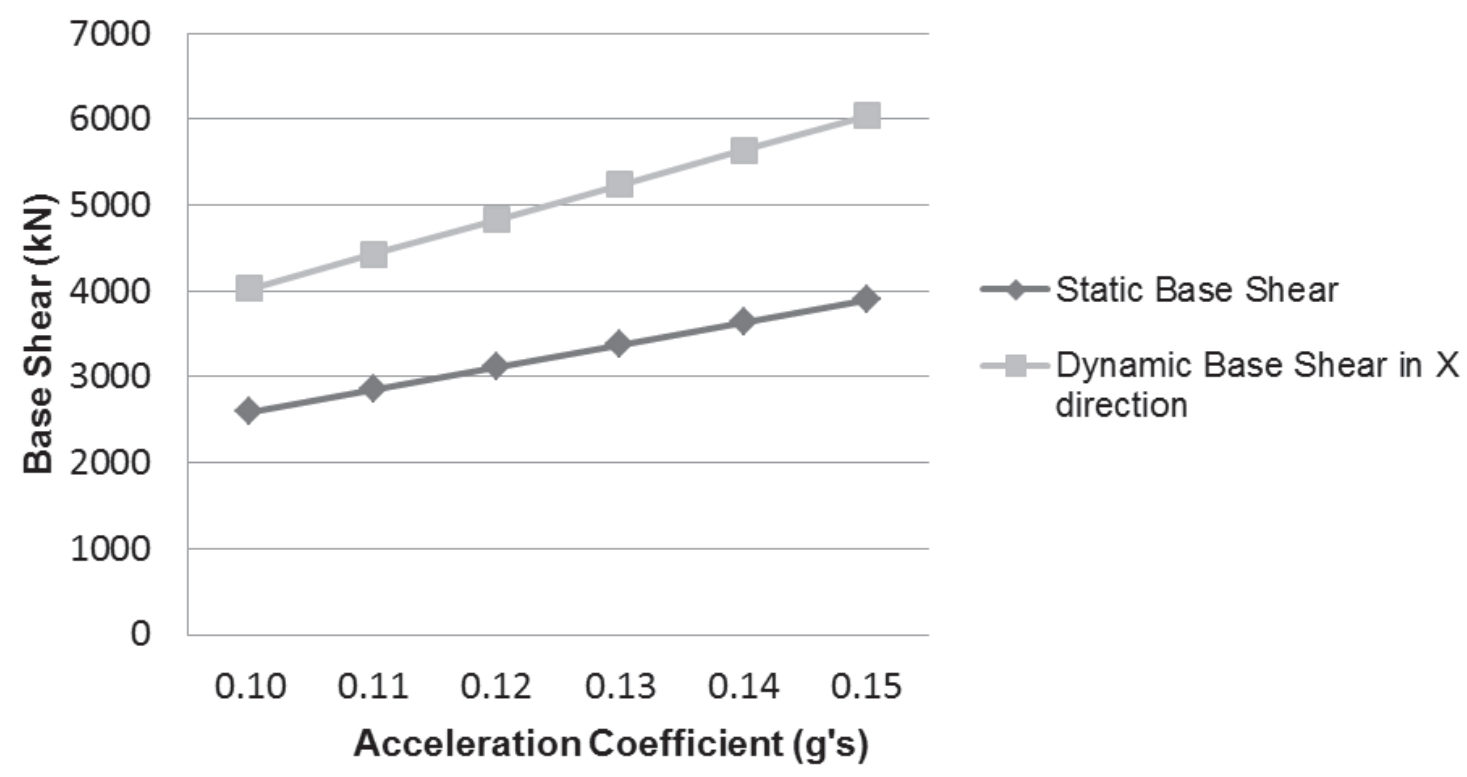

Figure 4 - Acceleration Coefficient vs. Base Shear - Building without Transfer Plate 
Figures 3 and 4 show the variation of the static base shear and dynamic base shear (according to AS1170.4) with the acceleration coefficient for the building with transfer plate and the one without a transfer plate, respectively. The resulting base shear values in the $\mathrm{X}$-direction are given for the response spectrum in the $\mathrm{X}$ direction (SpecX) and for the static earthquake forces that are applied in the X-direction (EQX). SpecX includes a 30\% component from the response spectrum in the $\mathrm{Y}$-direction (SpecY) as per the requirements of AS1170.4.

It can be seen that the base shear values increase linearly with the acceleration coefficient when it is varied from 0.10 to 0.15 . For comparison purposes, an acceleration coefficient was chosen as 0.12 (See Appendix A for calculations).

When Figures 3 and 4 are compared, it is evident that calculated static base shear is lower than the dynamic base shear for both buildings. This gives an indication that dynamic effects can be significant for acceleration values for the range considered.

\subsection{Results}

All results presented here are for the acceleration coefficient of 0.12 . All base shear and drift values are for the $\mathrm{X}$-direction and under the EQX and SpecX load cases.

The vertical distribution of static base shear is shown in Figure 5. (See Appendix A for calculations)

It can be seen that the static base shear value of the building with transfer plate is greater than that for the building without transfer plate. This is due to the higher mass of the transfer plate and the parking areas with a thicker floor slab in comparison with the residential floors in the building without transfer plate.

While the building without transfer plate follows a typical pattern of continuously increasing base shear components with height, the building with transfer plate has a sudden increase of the base shear component at Level 5 , i.e. the transfer plate level, and then a drop in the next level. This is due to the higher mass concentration at the transfer plate level.

However it should be noted that these values are mere fractions of base shear applicable at each level. What is important is the aggregate of these values at each level, i.e. the total distribution of base shear which is shown in Figure 6.

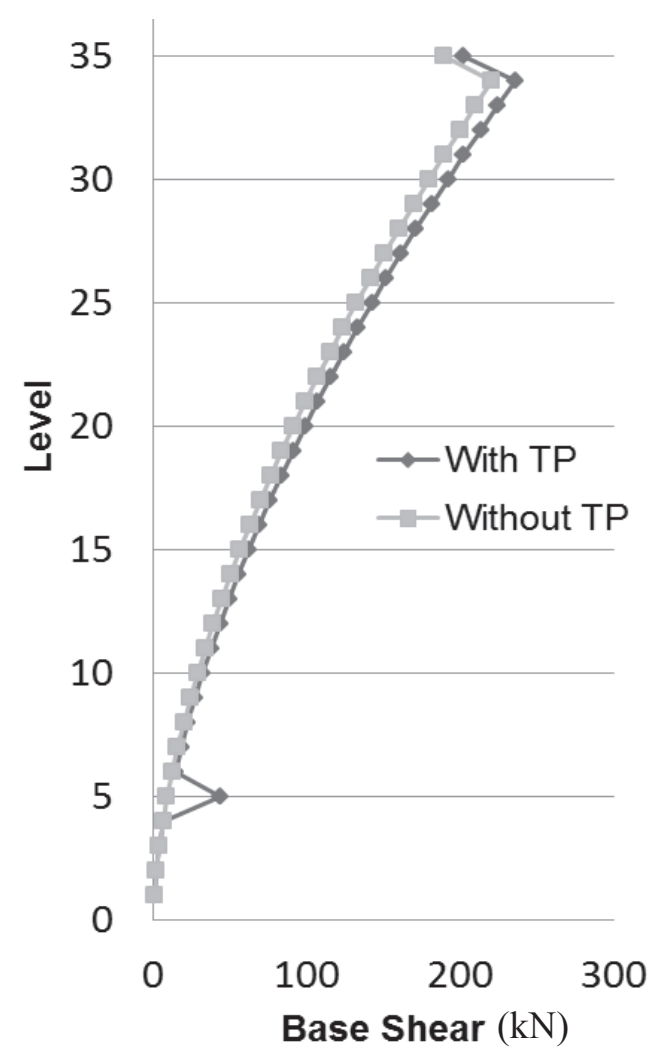

Figure 5 - Vertical Distribution of Static Base Shear

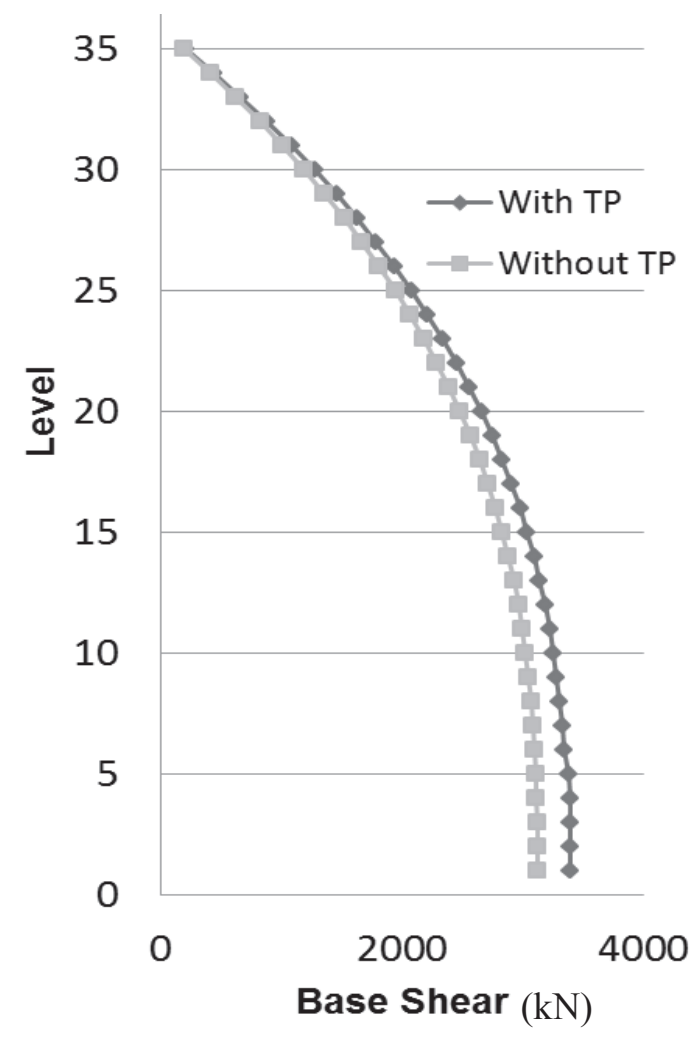

Figure 6 - Vertical Distribution of Total Static Base Shear 
The total static base shear distribution shows that although there is a sudden variation of individual storey forces at the transfer plate level, it is only a small variation in the total base shear distribution.

The total base shear distribution shows that the difference of the total shear applicable at the transfer plate level and just above that is only about $36 \mathrm{kN}$ which is not that significant in comparison with the total shear force applicable at that level which is about $3400 \mathrm{kN}$.

Thus, it can be seen that the building with transfer plate follows more or less the same pattern as the building without transfer plate when it comes to the total static shear distribution.

The vertical distribution of dynamic base shear and the total dynamic base shear are shown in Figures 7 and 8, respectively.

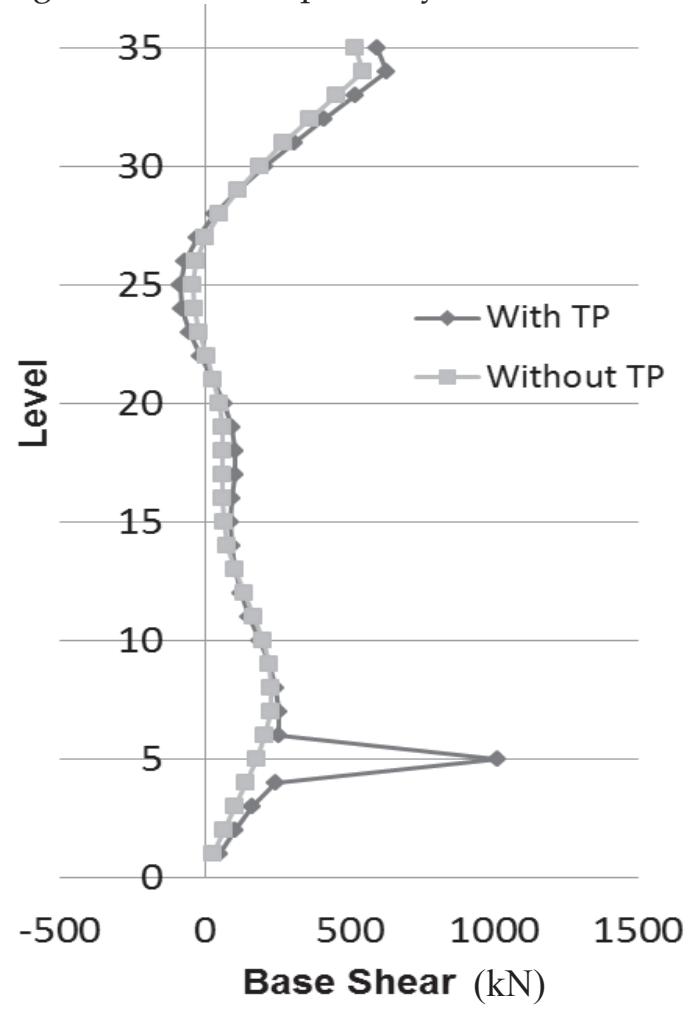

Figure 7 - Vertical Distribution of Dynamic Base Shear

The total dynamic shear distribution is significant here since it clearly shows a sudden and sizable increase at the transfer plate level. The difference between the total base shear value just before the transfer plate and that at the transfer plate level is about $1000 \mathrm{kN}$. Compared with the component of base shear at transfer plate level of $5700 \mathrm{kN}$, this is quite significant and thus it is clearly seen that the dynamic effects could be significant for the building with transfer plate.

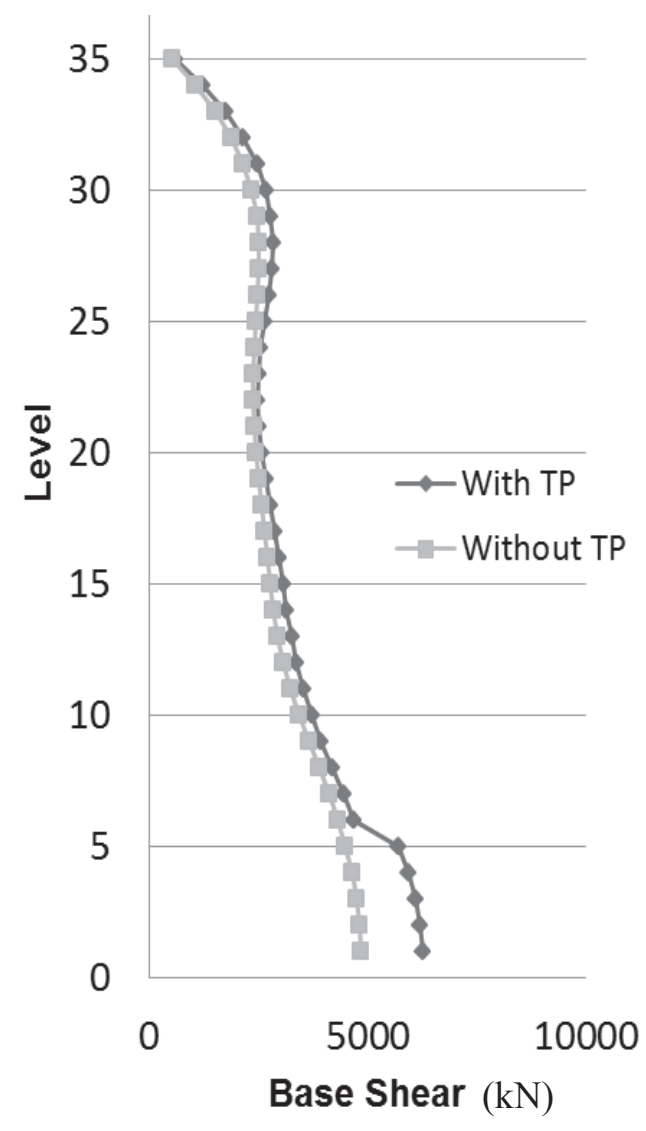
Figure 8 - Vertical Distribution of Total
Dynamic Base Shear

The total dynamic shear distribution for the building without transfer plate follows a similar pattern to its total static shear distribution. However, looking at the results, it is evident that dynamic base shear is critical for both the buildings.

Another critical factor that needs attention is the top deflection and lateral drifts for a building under lateral forces such as earthquakes. The top deflections and the lateral drifts are given in Table 1.

It is interesting to see what an optimum level would be for the transfer plate to be positioned. For this, the dynamic analysis was carried out for the building with transfer plate, keeping the transfer plate at different floors. As described earlier the dynamic effects were considered with an acceleration coefficient of 0.12 , and the resulting shear values in the $X$ direction are given here against the response spectrum case SpecX. 
Table 1 - Top Deflection \& Drift Index with Equivalent Static and Dynamic Analysis

\begin{tabular}{|c|c|c|c|c|c|}
\hline & & \multicolumn{2}{|c|}{$\begin{array}{c}\text { Transfer Plate Building } \\
\text { (Transfer Plate at } 5^{\text {th }} \text { Floor Level) }\end{array}$} & \multicolumn{2}{|c|}{ Building Without Transfer Plate } \\
\hline & & $\begin{array}{l}\text { Deflection } \\
(\mathrm{mm})\end{array}$ & $\begin{array}{l}\text { Drift } \\
\text { Index }\end{array}$ & $\begin{array}{l}\text { Deflection } \\
(\mathrm{mm})\end{array}$ & $\begin{array}{l}\text { Drift } \\
\text { Index }\end{array}$ \\
\hline Static & $\mathrm{a}=0.12$ & 44.8 & 0.00231 & 41.5 & 0.00207 \\
\hline \multirow{6}{*}{ Dynamic } & $\mathrm{a}=0.10$ & 28.3 & 0.00175 & 27.8 & 0.00164 \\
\hline & $\mathrm{a}=0.11$ & 31.1 & 0.00192 & 30.6 & 0.00180 \\
\hline & $\mathrm{a}=0.12$ & 32.9 & 0.00210 & 33.4 & 0.00196 \\
\hline & $a=0.13$ & 36.8 & 0.00228 & 36.2 & 0.00213 \\
\hline & $\mathrm{a}=0.14$ & 39.6 & 0.00245 & 39.0 & 0.00230 \\
\hline & $\mathrm{a}=0.15$ & 42.5 & 0.00262 & 41.8 & 0.00246 \\
\hline
\end{tabular}

The critical parameters taken into account here were the total dynamic base shear component at the transfer plate level and the dynamic base shear. The results are shown in Table 2.

Table 2 - Variation of Dynamic Base Shear with Transfer Plate Level

\begin{tabular}{|l|c|c|}
\hline $\begin{array}{c}\text { Transfer Plate } \\
\text { Level }\end{array}$ & $\begin{array}{c}\text { Base Shear } \\
(\mathrm{kN})\end{array}$ & $\begin{array}{c}\text { Shear } \\
\text { Component } \\
\text { at Transfer } \\
\text { Plate Level }\end{array}$ \\
\hline Second Floor & 5314 & 351 \\
\hline Third Floor & 5710 & 606 \\
\hline Fourth Floor & 6060 & 854 \\
\hline Fifth Floor & 6261 & 1014 \\
\hline
\end{tabular}

It is evident that there is an increase in the base shear as the transfer plate location is moved up. This indicates that it is advisable to have the transfer plate at a lower level. If it is essential to have it at a higher level, then adequate attention requires to be paid for the ductility needs of the columns and connections.

\section{Conclusions}

It should be noted that previous studies have indicated that the buildings with transfer plates can perform better under wind induced accelerations. Therefore, it is recommended to consider transfer plates as a member with favourable structural actions since it is an essential component of mixed developments.

Buildings without transfer plates perform better against earthquakes. This appears to be due to the regularity of its mass distribution as against that of buildings with transfer plates. It was observed that the building with a transfer plate could indicate higher top deflection and a greater base shear.

It was also clear through the findings of the research that a dynamic analysis needs to be carried out for buildings with irregular mass distributions such as those with transfer plates, since dynamic effects may prove to be more critical. This would need the aid of a 3D model of the structure.

It is advisable to consider transfer plates wherever they are needed. They should never be considered as a problematic feature though they may have some negative effects on the actual earthquake behaviour. It can be clearly seen that the presence of transfer plates can give rise to significant shear values at transfer plates. Thus, the columns located immediately under the transfer plates are the areas that may suffer the worst damage. Any formation of plastic hinges and associated crushing of concrete may have severe adverse effects. Therefore, it is advisable to pay very special attention to improve confinement to the columns as much as possible using the detailing practices (such as links and hooks details for reinforced concrete columns) recommended for enhanced earthquake resistance.

\section{References}

1. Abayakoon, S. B. S. (1995) Seismic Risk Analysis of SriLanka, Journal of the Geological Society of Sri Lanka, 6:65-72

2. AS1170.1:1989, Minimum Design Loads on Structures- Part 1: Dead and live loads and load combinations, Standards Australia, New South Wales. 
3. AS1170.4:1993, Minimum Design Loads on Structures- Part 4: Earthquake loads, Standards Australia, New South Wales.

4. Balasuriya S.S., Bandara K.M.K., Ekanayake S.D., Jayasinghe M.T.R. (2007), "The Influence of Transfer Plates on the Lateral Behaviour of Apartment Buildings", Engineer, Journal of Institution of Engineers, Sri Lanka, Volume XXXX, No: 4, October, pp 22-30

5. CHOPRA, A.K. (2001), 'Dynamics of Structures Theory and Application to Earthquake Engineering'. $2^{\text {nd }}$ edition Prentice Hall

6. COMARTIN C. D., NIEWIAROWSKI R.W., ROJAHN C. (1996), 'Seismic Evaluation and Retrofit of Concrete Buildings'. Volume 1, Applied Technology Council, USA

7. Peiris L.M.N., (2008), "Seismic Hazard Assessment of Sri Lanka and Seismic Risk in Colombo", Risk Management Solutions, London, UK

8. SAP2000 Analysis Reference, (2002), Computers and Structures, Inc., Berkeley, California, USA, Version 8.0

9. SMITH, B. S., COULL, A.(1991), 'TallBuilding Structures', John Wiley, USA

10. WILKINSON, S. (1997).'Seismicity and Ground Motion'. The Structural Branch of Engineers Australia

11. WILSON J., HUTCHINSON G. (1997), 'D ynamic Characteristics and Response'. The Structural Branch of Engineers Australia

12. WILSON, L. EDWARD.(1995),'Three Dimensional Static and Dynamic Analysis of Structures', Computers and structures, Inc., USA 


\section{Appendix A}

\section{Earthquake Load Calculations}

All calculations here are made in accordance with AS 1170.4 guidelines.

The depth of bed rock in Sri Lanka can be assumed to be in a range of $15 \mathrm{~m}$ to $20 \mathrm{~m}$.

Thus site factor $=1.0$

Building is classified under Type II

(Clause 2.2.3 - b)

Acceleration coefficients are taken in a range from 0.10 to 0.15 .

For the specimen calculations, the acceleration coefficient has been taken as 0.12 .

Importance factor, $\mathrm{I}=1.00$

(Table 2.5)

\section{Static Analysis}

For the building with the transfer plate;

$T=\frac{h_{n}}{s g}=\frac{8.6 \times 8 g}{s g}=2.172 g$

$c=\frac{1.23 \Omega}{\tau^{2} \mathrm{~s}}=\frac{1.28 \times 0.08}{2.172^{2 / 3}}=0.037$

$\mathrm{R}_{\mathrm{f}}=6.0$

$K_{d}=5.0$

(Table 6.2.6 - b)

$V=I\left(\frac{c s}{v_{f}}\right) G_{g}$

(Clause 6.2.2)

$V \geq 0.01 G_{g}$

$\mathrm{F}_{\mathrm{x}}=\mathrm{C}_{\mathrm{vx}} \mathrm{V}($ Clause 6.3)

$C_{v x}=\underline{\left(G_{g x} \underline{h}_{x} k\right)}$

$\left(\sum \mathrm{G}_{\mathrm{gi}} \mathrm{h}_{\mathrm{i}}^{\mathrm{k}}\right)$

The calculations have been carried out to find V (base shear) using a spreadsheet with the aid of the equations given above. 
Resulting Base shear $(\mathrm{V})=3390 \mathrm{kN}$

\begin{tabular}{|c|c|c|c|c|c|c|}
\hline Level & $\begin{array}{c}\mathrm{G}_{\mathrm{gx}} \\
(\mathrm{kN})\end{array}$ & $\begin{array}{c}\mathrm{h}_{\mathrm{x}} \\
(\mathrm{m})\end{array}$ & $h_{x}{ }^{k}$ & $G_{g x} \cdot h_{x}{ }^{k}$ & $C_{v x}$ & $\begin{array}{c}F_{x} \\
(k N)\end{array}$ \\
\hline 35 & 4399.86 & 106.3 & 2382.40 & 10482235 & 0.0594 & 201.4 \\
\hline 34 & 5395.62 & 103.3 & 2271.42 & 12255700 & 0.0695 & 235.4 \\
\hline 33 & 5395.62 & 100.3 & 2162.56 & 11668344 & 0.0661 & 224.2 \\
\hline 32 & 5395.62 & 97.3 & 2055.85 & 11092581 & 0.0629 & 213.1 \\
\hline 31 & 5395.62 & 94.3 & 1951.31 & 10528528 & 0.0597 & 202.3 \\
\hline 30 & 5395.62 & 91.3 & 1848.96 & 9976308 & 0.0565 & 191.7 \\
\hline 29 & 5395.62 & 88.3 & 1748.84 & 9436051 & 0.0535 & 181.3 \\
\hline 28 & 5395.62 & 85.3 & 1650.95 & 8907890 & 0.0505 & 171.1 \\
\hline 27 & 5395.62 & 82.3 & 1555.33 & 8391965 & 0.0476 & 161.2 \\
\hline 26 & 5395.62 & 79.3 & 1462.00 & 7888423 & 0.0447 & 151.5 \\
\hline 25 & 5395.62 & 76.3 & 1371.00 & 7397419 & 0.0419 & 142.1 \\
\hline 24 & 5395.62 & 73.3 & 1282.36 & 6919116 & 0.0392 & 132.9 \\
\hline 23 & 5395.62 & 70.3 & 1196.10 & 6453684 & 0.0366 & 124.0 \\
\hline 22 & 5395.62 & 67.3 & 1112.25 & 6001304 & 0.0340 & 115.3 \\
\hline 21 & 5395.62 & 64.3 & 1030.87 & 5562168 & 0.0315 & 106.9 \\
\hline 20 & 5395.62 & 61.3 & 951.97 & 5136479 & 0.0291 & 98.7 \\
\hline 19 & 5395.62 & 58.3 & 875.61 & 4724452 & 0.0268 & 90.8 \\
\hline 18 & 5395.62 & 55.3 & 801.82 & 4326319 & 0.0245 & 83.1 \\
\hline 17 & 5395.62 & 52.3 & 730.65 & 3942326 & 0.0223 & 75.7 \\
\hline 16 & 5395.62 & 49.3 & 662.16 & 3572740 & 0.0202 & 68.6 \\
\hline 15 & 5395.62 & 46.3 & 596.38 & 3217848 & 0.0182 & 61.8 \\
\hline 14 & 5395.62 & 43.3 & 533.39 & 2877960 & 0.0163 & 55.3 \\
\hline 13 & 5395.62 & 40.3 & 473.24 & 2553417 & 0.0145 & 49.1 \\
\hline 12 & 5395.62 & 37.3 & 416.00 & 2244590 & 0.0127 & 43.1 \\
\hline 11 & 5395.62 & 34.3 & 361.75 & 1951891 & 0.0111 & 37.5 \\
\hline 10 & 5395.62 & 31.3 & 310.58 & 1675778 & 0.0095 & 32.2 \\
\hline 9 & 5395.62 & 28.3 & 262.58 & 1416766 & 0.0080 & 27.2 \\
\hline 8 & 5395.62 & 25.3 & 217.85 & 1175443 & 0.0067 & 22.6 \\
\hline 7 & 5395.62 & 22.3 & 176.53 & 952482 & 0.0054 & 18.3 \\
\hline 6 & 5395.62 & 19.3 & 138.76 & 748676 & 0.0042 & 14.4 \\
\hline 5 & 21495.38 & 16.3 & 104.71 & 2250788 & 0.0128 & 43.2 \\
\hline 4 & 5757.06 & 12 & 62.86 & 361866 & 0.0021 & 7.0 \\
\hline 3 & 5369.87 & 9 & 38.92 & 208984 & 0.0012 & 4.0 \\
\hline 2 & 5369.87 & 6 & 19.80 & 106335 & 0.0006 & 2.0 \\
\hline 1 & 4476.35 & 3 & 6.24 & 27925 & 0.0002 & 0.5 \\
\hline Total & 203341.37 & & & 176434781 & & 3389.6 \\
\hline
\end{tabular}




\section{For the building without the transfer plate;}

Same values are used as for the building without the transfer plate. Only value that will differ is the dead weight of the building.

Resulting Base shear $(\mathrm{V})=3115 \mathrm{kN}$

\begin{tabular}{|c|c|c|c|c|c|c|}
\hline Level & $\begin{array}{c}\mathrm{G}_{\mathrm{gx}} \\
(\mathrm{kN})\end{array}$ & $\begin{array}{l}\mathrm{h}_{\mathrm{x}} \\
(\mathrm{m})\end{array}$ & $h_{x}{ }^{k}$ & $G_{g x} \cdot h_{x}{ }^{k}$ & $\mathrm{C}_{\mathrm{vx}}$ & $\begin{array}{c}\mathrm{F}_{\mathrm{x}} \\
(\mathrm{kN})\end{array}$ \\
\hline 35 & 4399.86 & 105 & 2334.05 & 10269486 & 0.06065 & 188.9 \\
\hline 34 & 5395.62 & 102 & 2223.98 & 11999763 & 0.07087 & 220.7 \\
\hline 33 & 5395.62 & 99 & 2116.05 & 11417416 & 0.06743 & 210.0 \\
\hline 32 & 5395.62 & 96 & 2010.28 & 10846713 & 0.06406 & 199.5 \\
\hline 31 & 5395.62 & 93 & 1906.69 & 10287772 & 0.06076 & 189.2 \\
\hline 30 & 5395.62 & 90 & 1805.30 & 9740720 & 0.05753 & 179.2 \\
\hline 29 & 5395.62 & 87 & 1706.14 & 9205688 & 0.05437 & 169.3 \\
\hline 28 & 5395.62 & 84 & 1609.23 & 8682811 & 0.05128 & 159.7 \\
\hline 27 & 5395.62 & 81 & 1514.61 & 8172234 & 0.04826 & 150.3 \\
\hline 26 & 5395.62 & 78 & 1422.28 & 7674106 & 0.04532 & 141.2 \\
\hline 25 & 5395.62 & 75 & 1332.30 & 7188586 & 0.04245 & 132.2 \\
\hline 24 & 5395.62 & 72 & 1244.68 & 6715838 & 0.03966 & 123.5 \\
\hline 23 & 5395.62 & 69 & 1159.47 & 6256039 & 0.03695 & 115.1 \\
\hline 22 & 5395.62 & 66 & 1076.68 & 5809374 & 0.03431 & 106.9 \\
\hline 21 & 5395.62 & 63 & 996.37 & 5376039 & 0.03175 & 98.9 \\
\hline 20 & 5395.62 & 60 & 918.57 & 4956243 & 0.02927 & 91.2 \\
\hline 19 & 5395.62 & 57 & 843.32 & 4550208 & 0.02687 & 83.7 \\
\hline 18 & 5395.62 & 54 & 770.66 & 4158171 & 0.02456 & 76.5 \\
\hline 17 & 5395.62 & 51 & 700.64 & 3780387 & 0.02233 & 69.5 \\
\hline 16 & 5395.62 & 48 & 633.32 & 3417132 & 0.02018 & 62.9 \\
\hline 15 & 5395.62 & 45 & 568.74 & 3068702 & 0.01812 & 56.4 \\
\hline 14 & 5395.62 & 42 & 506.97 & 2735420 & 0.01615 & 50.3 \\
\hline 13 & 5395.62 & 39 & 448.07 & 2417639 & 0.01428 & 44.5 \\
\hline 12 & 5395.62 & 36 & 392.12 & 2115748 & 0.01250 & 38.9 \\
\hline 11 & 5395.62 & 33 & 339.20 & 1830177 & 0.01081 & 33.7 \\
\hline 10 & 5395.62 & 30 & 289.38 & 1561407 & 0.00922 & 28.7 \\
\hline 9 & 5395.62 & 27 & 242.79 & 1309984 & 0.00774 & 24.1 \\
\hline 8 & 5395.62 & 24 & 199.52 & 1076528 & 0.00636 & 19.8 \\
\hline 7 & 5395.62 & 21 & 159.72 & 861762 & 0.00509 & 15.9 \\
\hline 6 & 5395.62 & 18 & 123.53 & 666542 & 0.00394 & 12.3 \\
\hline 5 & 5395.62 & 15 & 91.17 & 491903 & 0.00291 & 9.0 \\
\hline 4 & 5395.62 & 12 & 62.86 & 339148 & 0.00200 & 6.2 \\
\hline 3 & 5395.62 & 9 & 38.92 & 209986 & 0.00124 & 3.9 \\
\hline 2 & 5395.62 & 6 & 19.80 & 106845 & 0.00063 & 2.0 \\
\hline 1 & 4399.86 & 3 & 6.24 & 27448 & 0.00016 & 0.5 \\
\hline Total & 186855.18 & & & 169323966 & & 3114.8 \\
\hline
\end{tabular}

